\title{
Design and Research of Skin Injection Molded TPE Materials Based on Genetic Algorithm
}

\author{
Kui Yan, ${ }^{1,2}$ Yizhe Chen $\mathbb{D}^{1,2}$, Hui Wang $\mathbb{D}^{1,2}$ Cheng Gao, ${ }^{1,3}$ and Qiuyang Bai ${ }^{1,3}$ \\ ${ }^{1}$ Hubei Key Laboratory of Advanced Technology for Automotive Components, Wuhan University of Technology, \\ Wuhan 430070, China \\ ${ }^{2}$ Hubei Collaborative Innovation Center for Automotive Components Technology, Wuhan 430070, China \\ ${ }^{3}$ Hubei Engineering Research Center for Green \& Precision Material Forming, Wuhan 430070, China \\ Correspondence should be addressed to Yizhe Chen; yzchen@whut.edu.cn and Hui Wang; huiwang@whut.edu.cn
}

Received 31 May 2019; Revised 7 August 2019; Accepted 6 February 2020; Published 29 February 2020

Guest Editor: Peng Zhao

Copyright ( $) 2020$ Kui Yan et al. This is an open access article distributed under the Creative Commons Attribution License, which permits unrestricted use, distribution, and reproduction in any medium, provided the original work is properly cited.

\begin{abstract}
Thermoplastic elastomer (TPE) is a kind of new automotive interior material with high elasticity and strength. Traditional TPE materials were difficult to meet the new requirements of large-scale automotive interior parts with complex shape. In this study, the TPE material was prepared using different mass ratios with homopolymer polypropylene (PP), styrene-ethylene/butene-styrene copolymer (SEBS), naphthene oil (NO), magnesium stearate (MGST), and polytetrafluoroethylene (PTFE). A quality-prediction and multiobjective optimization method based on a genetic algorithm was applied. The parameters that had an important effect on the forming quality were selected using an orthogonal testing method. Results showed that using the proposed method, a new TPE material is obtained with excellent scratch resistance ability and high MFI. The mechanisms of the addition of PTFE and MGST were analysed according to SEM images. The peel strength of the optimized part was measured to prove the coating quality of TPE material.
\end{abstract}

\section{Introduction}

Soft tactile interior has great advantages in visual and tactile aspects, which became the mainstream of interior materials in the automotive field. The processing technologies of soft tactile interior mainly include slush, cathode mould, and positive film. But these processes have disadvantages of low utilization rate of materials, high equipment costs and requirements [1]. Skin injection molding indicates the process of two-step injection. The core material is injected into the mold firstly. After the curing of the core material, the skin material is injected into the mold, covering the core material [2]. This technology can be used to make soft touch materials covering the interior parts by injecting soft tactile materials on the surface. In the skin injection molding process, reasonable process parameter design [3] and accurate process parameter measurement [4] can improve the quality of the molded component. Compared with traditional forming methods, this process has positive effects of low cost, high production efficiency and material utilization rate. It can improve the design freedom of the products $[5,6]$. Thermoplastic elastomer (TPE) is a new material with low density, soft surface, and high elasticity and strength, which can be formed using injection. It is widely used as small interior decoration cladding parts such as automobiles and aeronautics. However, due to its poor fluidity and insufficient composite ability with polypropylene (PP), it cannot be used in large-size automotive door trim panels, dashboards, and other skin injection molding components. Srinivasan and Gupta [7] and Li $\mathrm{H}$ et al. [8] studied the mechanical properties and morphology of PP/SEBS/PC blends. It was found that adding SEBS into PP can improve the large deformation ability. But the small deformation performance was reduced. The addition of SEBS to PP/PC reduced the stress concentration of the blends and increased the overall yield strength of the matrix. Tiggemann et al. and Tomacheski et al. studied the influence of clay on the properties of SEBS/PP/oil thermoplastic elastomer $[9,10]$. It was found that the addition of clay enhanced the tensile strength of the material. When a certain amount of clay was added, the 
material showed the best mechanical properties. Ayaz et al. [11], Daneshpayeh et al. [12], and Ghasemi et al. [13] studied the impact strength and flexural strength of PP/LLDPE/ $\mathrm{TiO}_{2} /$ SEBS nanocomposites by the Taguchi test. Kim et al. [14] and Vuluga et al. [15] studied the effect of repeated recycling on the structure and morphology of SEBS/PP composites. It was found that repeated recycling would degrade the triblock copolymer in SEBS, resulting in a slight decrease in hardness and a significant increase in viscosity. Sengupta et al. $[16,17]$ studied the effects of compositions and processing conditions on the morphology and properties of SEBS/PP/oil thermoplastic elastomer blends. It was found that SEBS/PP/oil blends had a continuous morphology, their SEBS phases were oriented together, and PP phases were decomposed in the polystyrene domain under high strain, which increased the elongation of the blends.

Current research mainly focused on the modification of TPE materials, changing the proportion of materials and additives, so as to improve the mechanical properties and meet the needs of production and life. However, the problems of low material fluidity, poor composite ability, and scratch resistance ability were not solved well.

In this study, TPE materials with different mass ratios of SEBS, PP, NO, MGST, and PTFE were prepared, and the materials with high MFI and excellent scratch resistance were designed by using genetic algorithm. The materials had better mold adaptability in injection moulding and could meet the requirements of large-size automobile interior parts with complex shape. The mechanisms of the addition of PTFE and MGST were analysed according to SEM images. The peel strength of the optimized part was carried out to prove the coating quality of TPE material.

\section{Materials and Methods}

2.1. Experimental Materials, Instruments, and Optimization Method. The materials used in this study were homopolymer polypropylene (PP), styrene-ethylene/butene-styrene copolymer (SEBS), naphthene oil (NO), magnesium stearate (MGST), and polytetrafluoroethylene (PTFE). Compared with other lubricants, MGST can reduce the adsorption of the surface powder and improve the fluidity. The same quality of MGST is better than talc and magnesia. The reason for choosing PTFE is that it has the lowest friction coefficient, and a lubricious film can be formed on the surface of the part. It has good lubricity and wear resistance under shearing force and better performance under high load conditions. The detailed information of these materials can be found below.

The melt mass flow rate of $P P$ is $37 \mathrm{~g} / 10 \mathrm{~min}$. The properties of PP including density, hardness, notched impact strength, and tensile strength of $P P$ are $0.98 \mathrm{~g} / \mathrm{cm}^{3}, 70 \mathrm{R}$, $22 \mathrm{~J} / \mathrm{m}^{2}$, and $32 \mathrm{MPa}$, respectively. This material was produced by Sinopec Co., Ltd.

The YH-503 powdery SEBS has low viscosity. The mass ratio of $\mathrm{S}$ and $\mathrm{B}$ is $30 / 70$. The tensile strength, elongation, and hardness of the material are $26.5 \mathrm{MPa}, 480 \%$, and $75 \mathrm{~A}$, respectively. The SEBS was obtained from Yueyang Petrochemical Company.
The KN4010 naphthene oil also has low viscosity. The viscosity at the temperature of $100^{\circ} \mathrm{C}$ is $10.06 \mathrm{~mm}^{2} / \mathrm{s}$. The density and flash point of NO are $899.3 \mathrm{~kg} / \mathrm{m}^{3}$ and $215^{\circ} \mathrm{C}$. This material was obtained from Xinjiang Karamay Company.

The density and melting point of pure MGST are $1.028 \mathrm{~g} / \mathrm{cm}^{3}$ and $132^{\circ} \mathrm{C}$. For the PTFE powder used in this study, the particle size, density, and crystallinity are $0.2 \mu \mathrm{m}$, $2.3 \mathrm{~g} / \mathrm{cm}^{3}$, and $90-95 \%$, respectively. The authors bought MGST and PTFE from DuPont Company of USA.

The high-speed mixer used in this study is SHR-25A from Zhangjiagang Light Industry Machinery Factory Co., Ltd.

The screw extruder applied in the current research is SHJ-20 from Nanjing Janet Electrical and Mechanical Co., Ltd. In the forming process, the temperature of the feeding section was $170^{\circ} \mathrm{C}$. The temperature of the compression section and the metering section was $240^{\circ} \mathrm{C}$. The temperature of the head section was $220^{\circ} \mathrm{C}$ and the screw speed was first stabilized at a lower speed, and the molten material was discharged. After the head was extruded, the screw speed was stabled at $20 \mathrm{rpm}$.

The skin injection molding machine is HDX50, produced by Guangdong Haida Injection Molding Machine Co., Ltd. The injection conditions are shown in Table 1. For the injection molding process, mold temperature was important for the crystallinity of material. From Zhao's work, it can be found that low mold temperature was beneficial for the improvement of crystallinity degree but negative for the uniformity of crystallinity. Therefore, the mold temperature was chosen as $40^{\circ} \mathrm{C}$ in the current study [18].

The melt flow rate instrument was MFI-1211 bought from Chengde Jinjian Testing Instrument Co., Ltd. The mechanical test machine was CMT6104 from Metis Industrial Systems (China) Co., Ltd. The electric cross gravimeter was 430P-I from Erichsen Company, Germany. The type of chromometer was X-Rite Color-Eye 7000A from American Aceroy Company. The SEM analysis was conducted using JSM-IT300 in Wuhan University of Technology.

The multiobjective optimization method developed by our team in the paper [19] was used to confirm the raw material ratio of the TPE material. In this method, the parameters that have an important effect on the responses are selected using an orthogonal testing method, and then a central composite design experiment is performed using these parameters. A mathematical model considering a response and impact factors is developed using the response surface method. The optimal combination of the impact parameters is finally determined using the NSGA-II (Nondominated Sorting Genetic Algorithm II). Detailed algorithm of this method can be found in our previous paper, but the difference is in TPE material here. Optimization can be performed based on the mass ratios of SEBS, PP, NO, MGST, and PTFE. The solving process of the method is illustrated in Figure 1.

2.2. Sample Preparation. SEBS and PP were placed in a vacuum drying chamber and dried at $100^{\circ} \mathrm{C}$ for more than 12 hours to ensure that their moisture content was below 
TABLE 1: Injection conditions.

\begin{tabular}{lcc}
\hline Parameters & Value & Skeleton \\
& Coatings \\
\hline Melt temperature $\left({ }^{\circ} \mathrm{C}\right)$ & 200 & 240 \\
Mold temperature $\left({ }^{\circ} \mathrm{C}\right)$ & 40 & 40 \\
Injection temperature $\left({ }^{\circ} \mathrm{C}\right)$ & 104 & 3.0 \\
Injection time $(\mathrm{s})$ & 98 & 0.8 \\
V/P switching (filling volume percentage) & 80 & 98 \\
Holding pressure (percentage of filling pressure) & 20 & 80 \\
Holding time (s) & - & 10 \\
Cooling time $(\mathrm{s})$ & & 20 \\
\hline
\end{tabular}

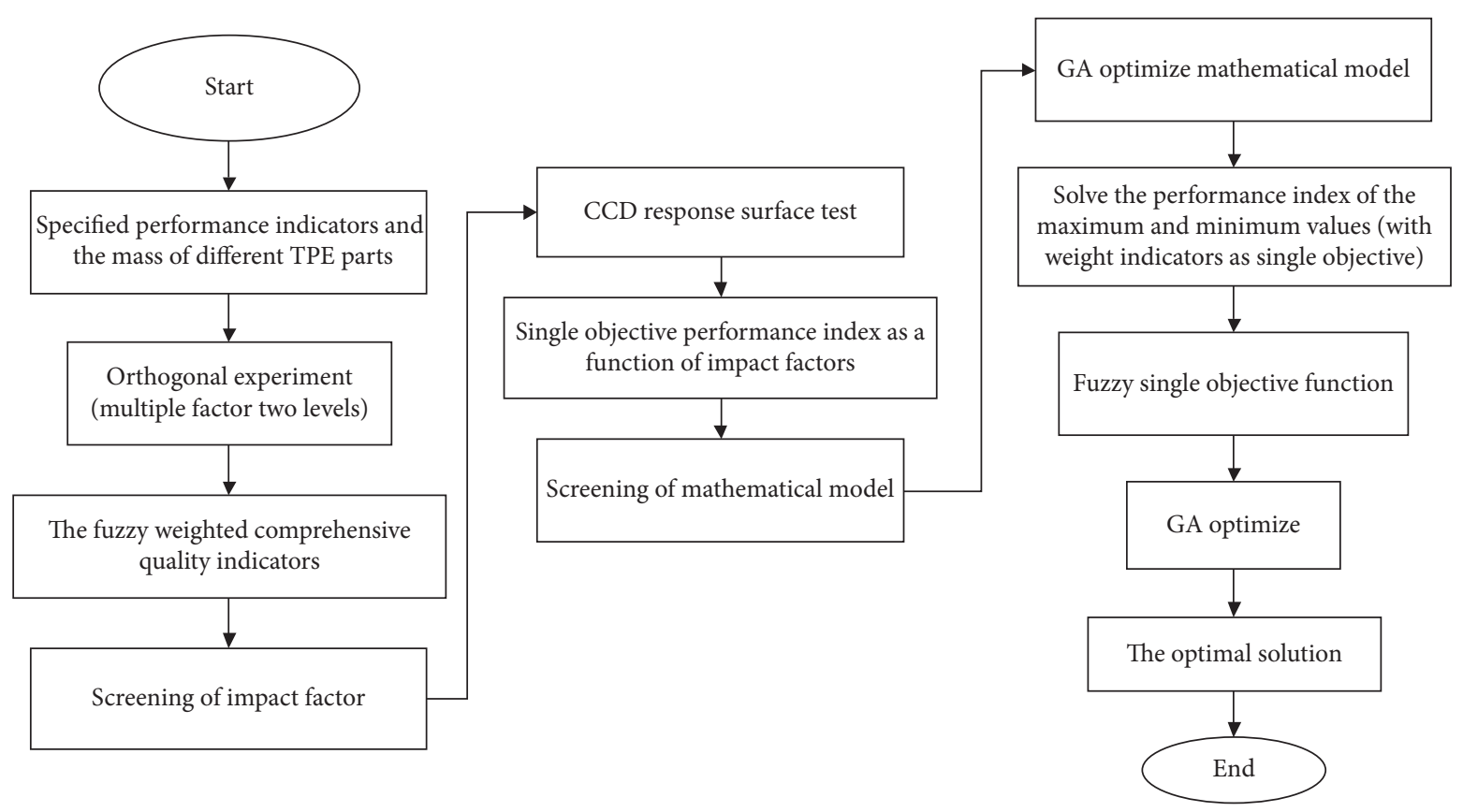

FIGURE 1: Solving process of the optimization method [19].

$0.02 \%$. The ratio of SEBS, NO, PP, MGST, and PTFE was defined as $A: B: C: D: E$. Firstly, the SEBS was put into the SHB-25A high-speed mixer, and then the temperature was decreased to room temperature. The NO was evenly sprinkled and mixed at a low speed of $500 \mathrm{r} / \mathrm{min}$ for $5 \mathrm{~min}$. The PP material, MGST, and PTFE were added to the mixer with a high speed of $1000 \mathrm{r} / \mathrm{min}$ for $5 \mathrm{~min}$, and then extruded in a TSE-40B twin-screw extruder. The pellets were then cut into test specimens by injection molding machine, as shown in Figure 2. Figure 2 shows a surface performance test piece based on the ISO7724 standard with a side length of $50 \mathrm{~mm}$ and a thickness of $4 \mathrm{~mm}$. Since the mass ratio of each component has a great influence on the performance of the TPE material, the mass ratio of SEBS, NO, PP, MGST, and PTFE was determined by orthogonal experimental design. The general notation for orthogonal tables is $\operatorname{Ln}(\mathrm{ap})$, where $p$ is the number of columns in the table (the number of factors), $n$ is the number of rows in the table, and $a$ is the number of levels. In this paper, 5 factors and 3 levels are selected; thus, the orthogonal table L27 (53) is used. The factors and levels are shown in Table 2.
According to the L27 (53) orthogonal table, at the same time, according to the factor level table shown in Table 2, 27 sets of test variable combinations were obtained, as shown in Table 3 .

The formulations of TPE were designed with different mass ratio. Then the material was granulated by an extruder. The melt index was tested. The TPE material was then injected into a square test piece for injection performance testing. For a goal of consistent results, each experiment was repeated three times.

\section{Results and Discussion}

3.1. Performance Testing and Characterization. The melt index was tested according to ASTM D1238-95. The test temperature is $230^{\circ} \mathrm{C}$, and the load is $2.16 \mathrm{~kg}$. The melt index of each group mixture is shown in Table 4 .

Scratch resistance ability was tested according to the following steps: the surface performance test samples of each component in Table 3 are taken, and each component was tested three times. The test load was $1 \mathrm{~kg}$, and the scratch rate 


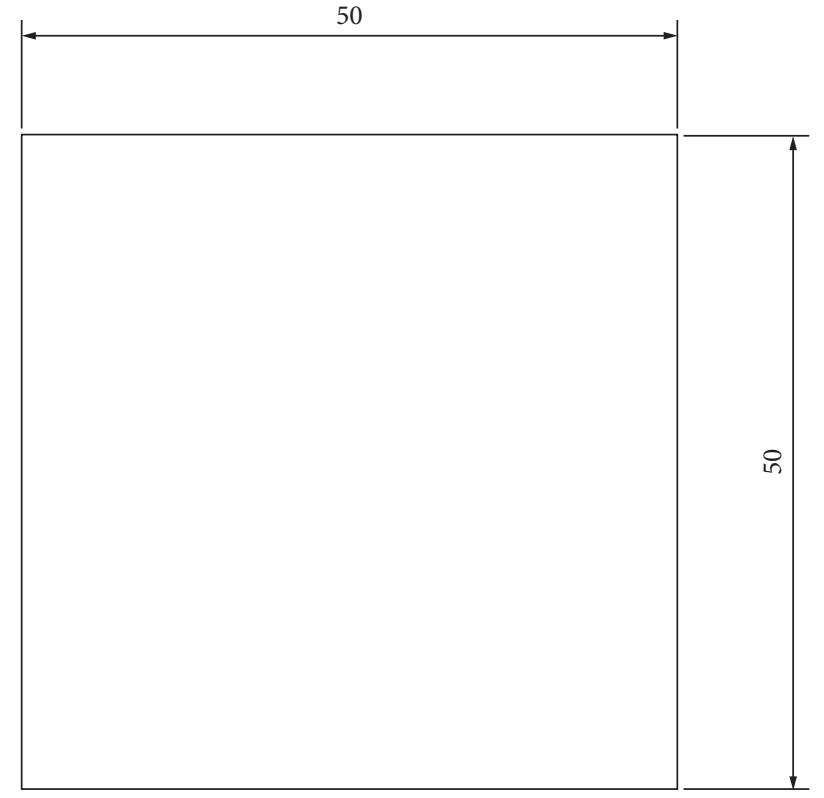

Figure 2: Test sample of surface performance.

Table 2: Factors and levels.

\begin{tabular}{lccccc}
\hline \multirow{2}{*}{ Level } & $A(\mathrm{SEBS})$ & $B(\mathrm{NO})$ & $C(\mathrm{PP})$ & $D(\mathrm{MGST})$ & $E(\mathrm{PTFE})$ \\
\hline 1 & 100 & 120 & 50 & 0 & 0 \\
2 & 110 & 130 & 60 & 20 & 20 \\
3 & 120 & 140 & 70 & 40 & 40 \\
\hline
\end{tabular}

TABLE 3: Test variables.

\begin{tabular}{lccccc}
\hline No. & $A$ & $B$ & $C$ & $D$ & $E$ \\
\hline 1 & 100 & 120 & 50 & 0 & 0 \\
2 & 100 & 120 & 50 & 0 & 20 \\
3 & 100 & 120 & 50 & 0 & 40 \\
4 & 100 & 130 & 60 & 20 & 0 \\
5 & 100 & 130 & 60 & 20 & 20 \\
6 & 100 & 130 & 60 & 20 & 40 \\
7 & 100 & 140 & 70 & 40 & 0 \\
8 & 100 & 140 & 70 & 40 & 20 \\
9 & 100 & 140 & 70 & 40 & 40 \\
10 & 110 & 120 & 60 & 40 & 0 \\
11 & 110 & 120 & 60 & 40 & 20 \\
12 & 110 & 120 & 60 & 40 & 40 \\
13 & 110 & 130 & 70 & 0 & 0 \\
14 & 110 & 130 & 70 & 0 & 20 \\
15 & 110 & 130 & 70 & 0 & 40 \\
16 & 110 & 140 & 50 & 20 & 0 \\
17 & 110 & 140 & 50 & 20 & 20 \\
18 & 110 & 140 & 50 & 20 & 40 \\
19 & 120 & 120 & 70 & 20 & 0 \\
20 & 120 & 120 & 70 & 20 & 20 \\
21 & 120 & 120 & 70 & 20 & 40 \\
22 & 120 & 130 & 50 & 40 & 0 \\
23 & 120 & 130 & 50 & 40 & 20 \\
24 & 120 & 130 & 50 & 40 & 40 \\
25 & 120 & 140 & 60 & 0 & 0 \\
26 & 120 & 140 & 60 & 0 & 20 \\
27 & 120 & 140 & 60 & 0 & 40 \\
\hline
\end{tabular}

TABLE 4: Test average of TPE material properties.

\begin{tabular}{lcc}
\hline No. & MFI $(\mathrm{g} / 10 \mathrm{~min})$ & Scratch resistance $\Delta L^{*}$ \\
\hline 1 & 106.25 & 1.49 \\
2 & 95.43 & 0.96 \\
3 & 79.21 & 0.47 \\
4 & 139.55 & 1.82 \\
5 & 121.32 & 1.27 \\
6 & 96.28 & 0.55 \\
7 & 162.33 & 2.42 \\
8 & 147.32 & 1.58 \\
9 & 126 & 0.69 \\
10 & 152.45 & 2.15 \\
11 & 131.12 & 1.42 \\
12 & 110.35 & 0.58 \\
13 & 109.42 & 1.36 \\
14 & 97.24 & 0.89 \\
15 & 81.24 & 0.43 \\
16 & 140.25 & 1.75 \\
17 & 122.41 & 1.09 \\
18 & 97.26 & 0.49 \\
19 & 159.34 & 1.97 \\
20 & 143.21 & 1.24 \\
21 & 106.32 & 0.64 \\
22 & 155.23 & 2.04 \\
23 & 133.87 & 1.57 \\
24 & 111.75 & 0.66 \\
25 & 110.84 & 1.21 \\
26 & 99.43 & 0.78 \\
27 & 86.88 & 0.39 \\
\hline & &
\end{tabular}

was $1000 \mathrm{~mm} / \mathrm{min}$. At least 20 parallel scratch lines were produced with a spacing of $2 \mathrm{~mm}$. Each sample was subjected to 5 separate tests, one in the middle and four in the corner (as shown in Figure 3), and the result was the average of the five values. The scratch resistance of each group of surface test samples is shown in Table $4 . \Delta L^{*}$ is the amount 


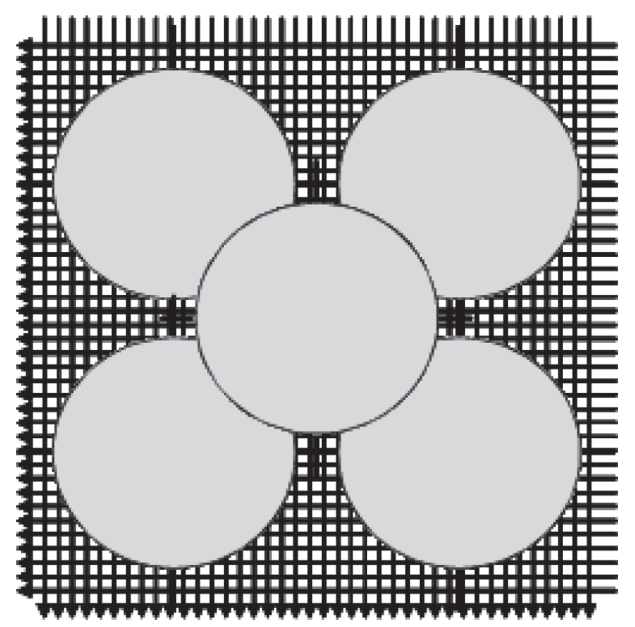

Figure 3: Test point location.

of the variation of value before and after the test. The smaller the value of $\Delta L^{*}$, the better the scratch resistance of the surface of the model.

In order to find the best mathematical model of the two goals of MFI and scratch resistance, considering the interaction of each variable, the fitting method of linear interaction curve was adopted in the software Minitab to obtain the relationship between the melt index and the variable. The fitting relationship is shown in the following formula:

lopenup3

$$
\begin{aligned}
\text { MFI }= & -1178+12.34 A+16.50 B-16.92 C \\
& +1.140 \quad D+34.1 E-0.1535 A * B \\
& +0.1332 A * C-0.213 A * E \\
& +0.0157 B * C-0.299 B * E \\
& -0.153 C * E-0.00540 D * E \\
& +0.00187 A * B * E-0.00047 A \\
& * C * E+0.00164 B * C * E,
\end{aligned}
$$

Scratch resistance $=-12.2+0.217 A+0.1729 B-0.315 C$

$$
\begin{aligned}
& +0.01971 D-0.111 E-0.002267 A \\
& * B+0.001267 A * C-0.00013 A \\
& * E+0.001317 B * C-0.00147 B \\
& * E+0.00653 C * E-0.000448 D \\
& * E+0.000021 A * B * E-0.000041 A \\
& * C * E-0.000016 B * C * E .
\end{aligned}
$$

The multiobjective optimization of the surface qualities during the injection molding was developed according to the regression fitting, and the mathematical model is described as

$$
\begin{aligned}
& \text { minimize } y 1, y 2 \text {, } \\
& y 1=-1178+12.34 A+16.50 B \\
& -16.92 C+1.140 \\
& D+34.1 E-0.1535 A \\
& \text { * B }+0.1332 A * C \\
& -0.213 A * E+0.0157 B \\
& * C-0.299 B * E-0.153 C \\
& \text { * E }-0.00540 \\
& D * E+0.00187 A \\
& \text { * } B * E-0.00047 A * C \\
& * E+0.00164 B * C * E \text {, } \\
& y 2=-12.2+0.217 A+0.1729 B \\
& -0.315 C+0.01971 \\
& D-0.111 E-0.002267 A \\
& * B+0.001267 A * C \\
& -0.00013 A * E \\
& +0.001317 B * C \\
& -0.00147 B * E+0.00653 C \\
& \text { * } E-0.000448 \\
& D * E+0.000021 A * B \\
& \text { * } E-0.000041 A * C * E \\
& -0.000016 B * C * E \text {, } \\
& -1<A, B, C, D, E<1 \text {, }
\end{aligned}
$$

where $y 1$ and $y 2$ denote the MFI and scratch resistance, respectively, and $A, B, C, D$, and $E$ are the impact parameters in Tables 2 and 3.

The multiobjective genetic algorithm was used to perform the optimization. The multiobjective optimization was implemented by the following steps:

Step 1: the $\min / \max$ values for MFI $\left(\operatorname{Min}_{\mathrm{MF}} / \mathrm{Max}_{\mathrm{MF}}\right)$ and scratch resistance $\left(\mathrm{Min}_{\mathrm{SR}} / \mathrm{Max}_{\mathrm{SR}}\right)$ were determined within the specified domain of the impact factors by using min and max functions.

Step 2: the objective functions (MFI and scratch resistance) were fuzzy, where the parameters $a$ and $b$ for the MFI and scratch resistance were set as minimum and maximum, respectively, and $k=1$ was used. The mapped objective functions were set as the multiobjective fitness functions and were described as

$$
\begin{aligned}
& f_{1}=\frac{1}{\left(\operatorname{Max}_{\mathrm{MF}}-\operatorname{Min}_{\mathrm{MF}}\right)}\left(y_{1}-\operatorname{Min}_{\mathrm{MF}}\right), \\
& f_{2}=\frac{1}{\left(\operatorname{Max}_{\mathrm{SR}}-\operatorname{Min}_{\mathrm{SR}}\right)}\left(y_{2}-\operatorname{Min}_{\mathrm{SR}}\right) .
\end{aligned}
$$




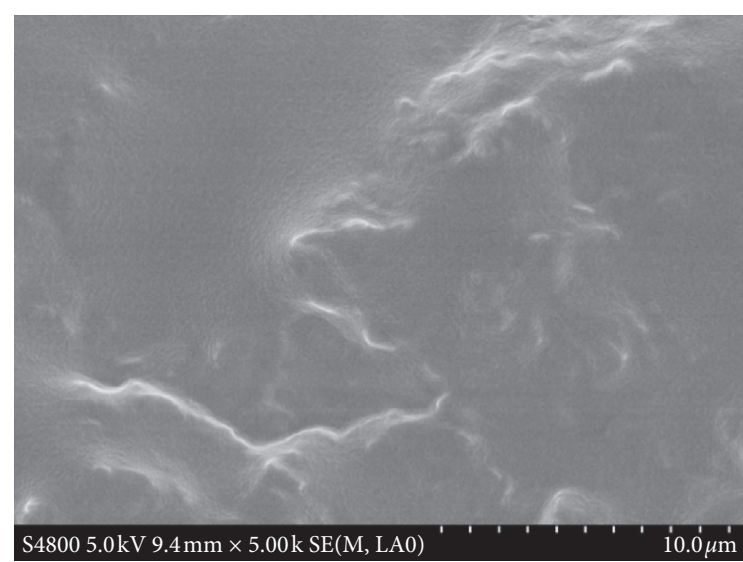

(a)

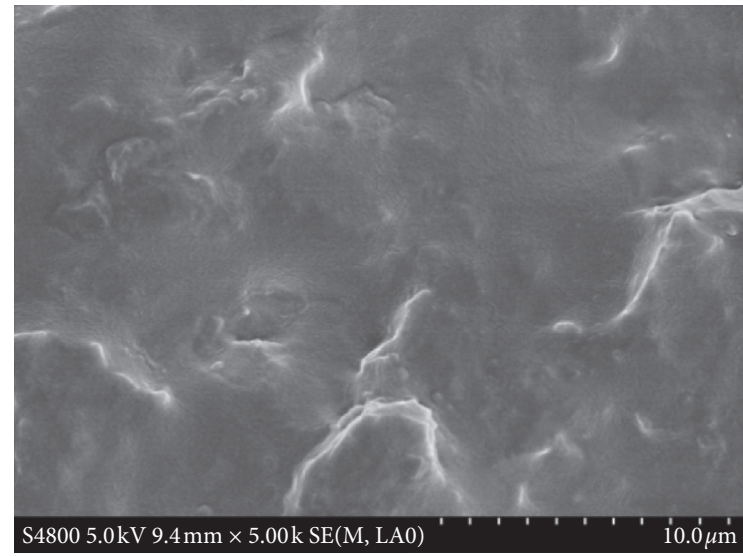

(c)

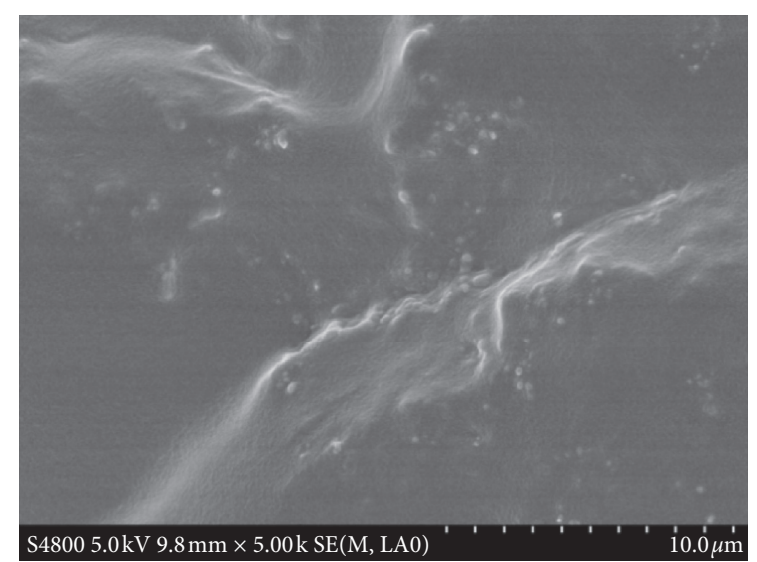

(b)

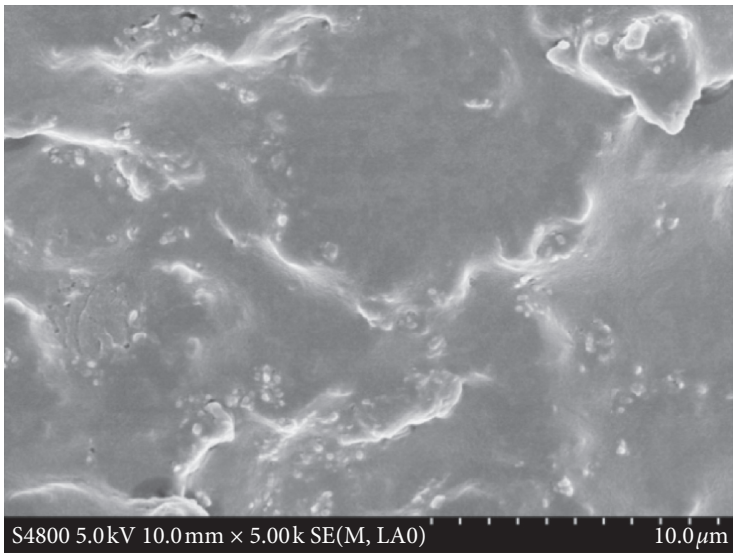

(d)

Figure 4: SEM images of samples of (a) original TPE, (b) TPE with MGST, (c) TPE with PTFE, and (d) TPE with MGST and PTFE.

Step 3: the optimal front set, population, and fitness function deviation were set to be 50,200 and 1e-100. The multiobjective genetic algorithm was used to calculate its Pareto optimal solution set. According to the requirements of the quality of the components, MFI and scratch resistance are both very important. Therefore, the nearest solution to the origin of the distance coordinates was selected as the final solution of this study. The optimal parameters were obtained: SEBS is 109.972 , naphthenic oil is 139.978 , PP is 40.01, MGST is 38.7 , and PTFE is 7.23. The combination of these parameters yielded a maximum MFI of $170.25 \mathrm{~mm}$ and minimum scratch resistance of 0.29 .

3.2. Mechanism Analysis. It is well known that the MGST and PTFE have obvious influence on the scratch resistance ability. Therefore, the surface topographies of the samples with or without these two compositions were obtained using SEM observation, as shown in Figure 4. Figure 4(a) is the image of the original TPE (the material contains only SEBS, NO and PP, and without MGST and PTFE). Figure 4(b) is an SEM image of TPE with additional PTFE sample, and Figure $4(\mathrm{c})$ is a TPE sample with MGST. Figure $4(\mathrm{~d})$ is the
SEM image of the sample with the addition of MGST and PTFE.

Comparing Figures 4(a) and 4(b), it can be seen that after the addition of PTFE to the TPE matrix, granules appear in the dispersed phase of the matrix. Since PTFE is a layered crystal structure formed with van der Waals force, the molecules are easily released. Therefore, when PTFE and TPE matrix are mixed, melted, granulated, and injected, the molecules of PTFE fall off and combine with TPE. The dualpreferred transfer film is preferentially formed on the dual surface. The adhesive wear changes to abrasive wear, which significantly improves the scratch resistance of the material. Comparing Figures 4(a) and 4(c), it can be seen that after the addition of MGST to the TPE matrix, the originally larger dispersed phase is changed to a large number of small dispersed phases. The interfacial tension of the material, while some of the potholes are filled by the small dispersed phase, can significantly increase the melt index of the material. Comparing Figures 4(c) and 4(d), it can be seen that with the addition of MGST and PTFE to the TPE matrix, the PTFE abrasive particles can be combined with the small dispersion. The MFI is reduced due to the lower cohesion and adhesion of the abrasive particles. At the same time, since MGST is more likely to be adhesive wear, the material 


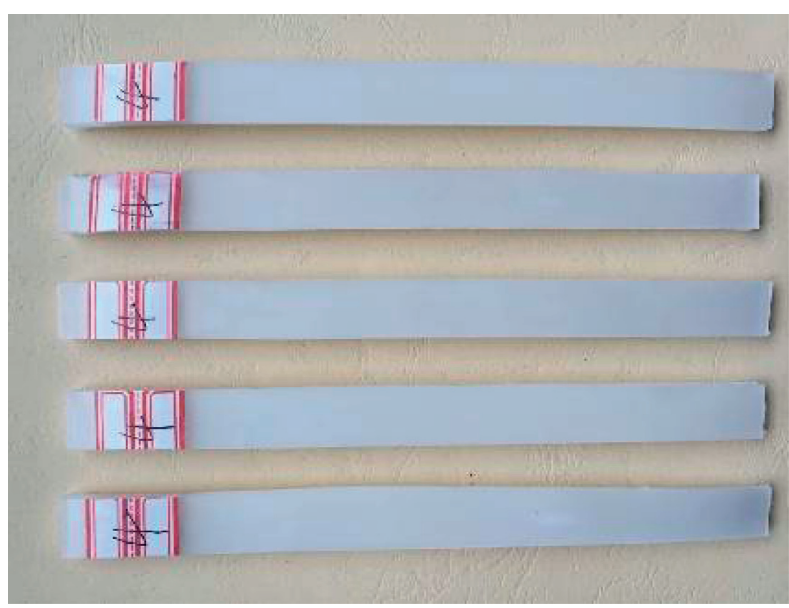

(a)

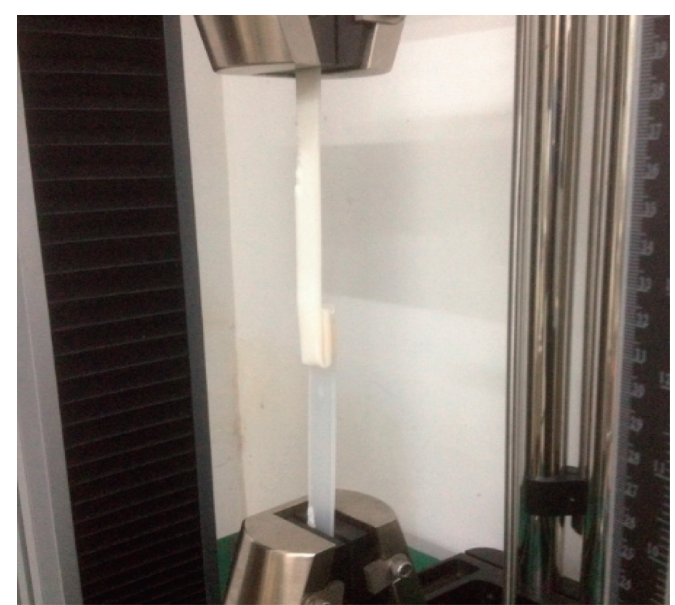

(b)

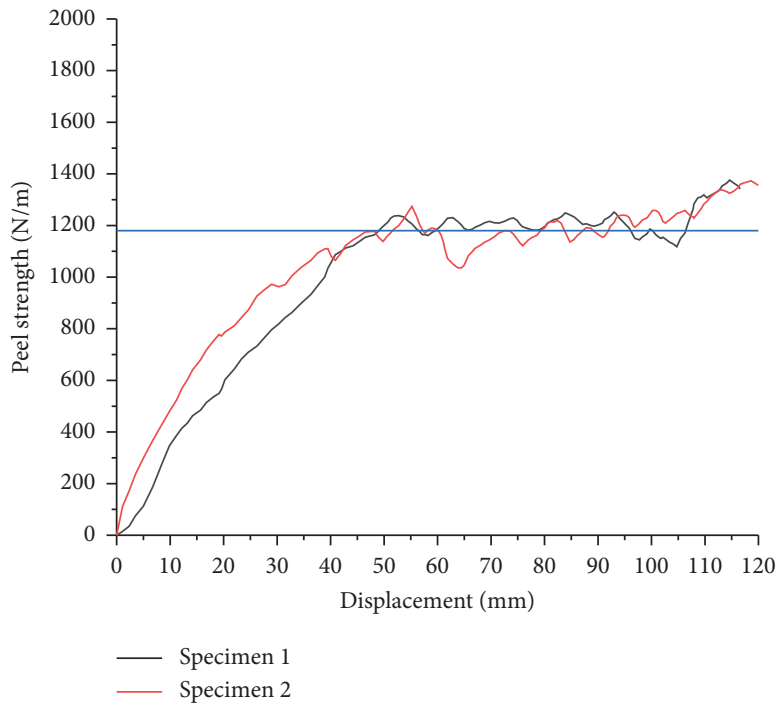

(c)

Figure 5: (a) Testing sample, (b) testing process, and (c) strength-displacement curve.

is mainly characterized by abrasive wear accompanied with slight adhesive wear.

3.3. Peel Strength Verification. In order to get the mechanical properties of optimized material, the peel strength test was carried out. As shown in Figure 5(a), the formed sample was processed into a rectangular spline $(170 \times 10 \mathrm{~mm})$ to perform a peeling test. The test was referred to GB/T2790-1995, the peeling rate was $50 \mathrm{~mm} / \mathrm{min}$, and the test was carried out at room temperature. In most interior parts of automobiles, the adhesion of the surface cladding to the skeleton needs to be greater than $525 \mathrm{~N} / \mathrm{m}$ (refer to GMW 14892-2012). In the peeling test, a part of the TPE material was previously separated from the PP material. The TPE and PP materials were, respectively, placed on the upper and lower ends of the testing machine (as shown in Figure 5(b)). As the displacement of the tester beam increased, the deformation was carried out. The tensile force of the TPE material was also improved continuously. Finally, as the peeling progressed, the peeling force of the two materials gradually stabilized. As shown in Figure 5(c), the average peel strength at which the spline peel strength tends to be stable is indicated by a horizontal straight line. It can be seen from the figure that the curve shows an upward trend when the displacement is $<50 \mathrm{~mm}$, and the peel strength tends to be stable after the displacement $\geq 50 \mathrm{~mm}$. The average peeling value is close to $1200 \mathrm{~N} / \mathrm{m}$ (greater than $525 \mathrm{~N} / \mathrm{m}$ ), indicating that the optimized sample has good coating properties.

\section{Conclusion}

The automotive interior material requires soft touch, excellent injection performance, and good surface scratch resistance. In order to achieve these goals, the TPE material was modified to obtain the optimal ratio of components by using genetic algorithm. The ideal material with low surface hardness, high MFI, and excellent scratch resistance was obtained. The specific results are as follows: 
(1) The parameters were selected using an orthogonal testing method. The optimized ratio of SEBS, PP, NO, MGST, and PTFE of TPE material can be obtained using genetic algorithm. The optimal parameters were obtained as follows: SEBS is 109.972, NO is $139.978, \mathrm{PP}$ is $40.01, \mathrm{MGST}$ is 38.7 , and PTFE is 7.23. Using the optimized results, the TPE material has higher MFI of 170.25 and scratch resistance of 0.29 .

(2) When PTFE and TPE matrix were mixed, melted, granulated, and injected, the molecules of PTFE fall off and combine with TPE. The dual-preferred transfer film was preferentially formed on the dual surface. The adhesive wear changed to abrasive wear, which significantly improved the scratch resistance of the material.

(3) After the addition of MGST to the TPE matrix, the originally larger dispersed phase was changed to a large number of small dispersed phases. The interfacial tension of the material, while some of the potholes were filled by the small dispersed phase, can significantly increase the MFI of the material.

(4) When both MGST and PTFE were added to the original TPE material, the PTFE abrasive particles can be combined with the small dispersion. The MFI was reduced due to the lower cohesion and adhesion of the abrasive particles. The material was mainly characterized by abrasive wear accompanied with slight adhesive wear. The results of peel strength test proved that the average peeling value is close to $1200 \mathrm{~N} / \mathrm{m}$ (greater than $525 \mathrm{~N} / \mathrm{m}$ ), indicating that the optimized sample had excellent coating properties.

\section{Data Availability}

The data used to support the findings of this study are included within the article.

\section{Conflicts of Interest}

The authors declare that they have no conflicts of interest.

\section{Acknowledgments}

The authors would like to acknowledge the financial support from the National Natural Science Foundation Council of China (Grant nos. 51775398 and 51805392), the 111 Project (Grant no. B17034), the Program for Innovative Research Team in University of Education Ministry (Grant no. IRT_17R83), the Nature Science Foundation of Hubei Province (Grant no. 2018CFB595), and the Fundamental Research Funds for the Central Universities (Grant nos. WUT:2018III074GX and 2018III067GX).

\section{References}

[1] W. Zhang, H. Chang, Y. Dou et al., "Polyurethane slush powders for instrument panel of automobiles: composition, processing and rheological properties," Materials Review, vol. 32, no. 12, pp. 4392-4397, 2018.

[2] M. Viana, D. Martino, A. J. Pontes, and J. C. au, "Co-injection molding of immiscible polymers: skin-core structure and adhesion studies," Polymer Engineering \& Science, vol. 51, no. 12, pp. 2398-2407, 2011.

[3] H. Daniel, "Multivariate process analysis for the prediction of injection molded part quality," 2019.

[4] J. Zhang, P. Zhao, Y. Zhao, J. Huang, N. Xia, and J. Fu, "Online measurement of cavity pressure during injection molding via ultrasonic investigation of tie bar," Sensors and Actuators A: Physical, vol. 285, pp. 118-126, 2019.

[5] L. Y. Hsieh and K.-H. Chang, "Yield improvement on in-mold decoration manufacturing through parameter optimization," International Journal of Precision Engineering and Manufacturing, vol. 14, no. 10, pp. 1823-1828, 2013.

[6] V Goodship, "Design and manufacture of plastic components for multifunctionality," in Injection Molding of Thermoplastics, pp. 103-170, Springer, Berlin, Germany, 2016.

[7] K. R. Srinivasan and A. K. Gupta, "Mechanical properties and morphology of PP/SEBS/PC blends," Journal of Applied Polymer Science, vol. 53, no. 1, pp. 1-17, 1994.

[8] H. Li, X. Sui, and X. M. Xie, "Correlation of morphology evolution with superior mechanical properties in PA6/PS/PP/ SEBS blends compatibilized by multi-phase compatibilizers," Chinese Journal of Polymer Science, vol. 36, no. 7, pp. 848-858, 2018.

[9] H. M. Tiggemann, V. F. Ribeiro, F. Celso, and S. M. B. Nachtigall, "Effect of commercial clays on the properties of SEBS/PP/oil thermoplastic elastomers. Part 1: physical, mechanical and thermal properties," Applied Clay Science, vol. 109-110, pp. 151-156, 2015.

[10] D. Tomacheski, M. Pittol, C. E. Ermel, D. N. Simões, V. F. Ribeiro, and R. M. C. Santana, "Influence of processing conditions on the mechanical properties of SEBS/PP/oil blends," Polymer Bulletin, vol. 74, no. 11, pp. 1-15, 2017.

[11] M. Ayaz, S. Daneshpayeh, and A. Noroozi, "Enhancing the impact and flexural strength of PP/LLDPE/TiO2/SEBS nanocomposites by using Taguchi methodology," Composites Science and Technology, vol. 129, pp. 61-69, 2016.

[12] S. Daneshpayeh, F. Ashenai Ghasemi, I. Ghasemi, and M. Ayaz, "Predicting of mechanical properties of PP/ LLDPE/ $\mathrm{TiO}_{2}$ nano-composites by response surface methodology," Composites Part B: Engineering, vol. 84, pp. 109120, 2016.

[13] F. A. Ghasemi, S. Daneshpayeh, I. Ghasemi, and M. Ayaz, "An investigation on the Young's modulus and impact strength of nanocomposites based on polypropylene/linear low-density polyethylene/titan dioxide (PP/LLDPE/TiO ${ }_{2}$ ) using response surface methodology," Polymer Bulletin, vol. 73, no. 6, pp. 1741-1760, 2016.

[14] J.-K. Kim, C.-H. Kim, and M.-H. Park, "Effects of multiple recycling on the structure and morphology of SEBS/PP composites," Bulletin of the Korean Chemical Society, vol. 37, no. 6, pp. 820-825, 2016.

[15] Z. Vuluga, D. M. Panaitescu, C. Radovici, C. Nicolae, and M. D. Iorga, "Effect of SEBS on morphology, thermal, and mechanical properties of PP/organoclay nanocomposites," Polymer Bulletin, vol. 69, no. 9, pp. 1073-1091, 2012.

[16] P. Sengupta and J. W. M. Noordermeer, "Effects of composition and processing conditions on morphology and properties of thermoplastic elastomer blends of SEBS-PP-oil and dynamically vulcanized EPDM-PP-oil," Journal of Elastomers \& Plastics, vol. 36, no. 4, pp. 307-331, 2004. 
[17] W. G. F. Sengers, P. Sengupta, J. W. M. Noordermeer, S. J. Picken, and A. D. Gotsis, "Linear viscoelastic properties of olefinic thermoplastic elastomer blends: melt state properties," Polymer, vol. 45, no. 26, pp. 8881-8891, 2004.

[18] P. Zhao, W. Yang, X. Wang, J. Li, B. Yan, and J. Fu, "A novel method for predicting degrees of crystallinity in injection molding during packing stage," Proceedings of the Institution of Mechanical Engineers, Part B: Journal of Engineering Manufacture, vol. 233, no. 1, pp. 204-214, 2019.

[19] Z. Yuan, H. Wang, X. Wei et al., "Multiobjective optimization method for polymer injection molding based on a genetic algorithm," Advances in Polymer Technology, vol. 2019, Article ID 9012085, 17 pages, 2019. 